\title{
INCLUSÃO DIGITAL, CONTROLES, VIGILÂNCIAS E LINHAS DE FUGA
}

\author{
DIGITAL INCLUSION, CONTROLS, SURVEILLANCES AND LINES OF FLIGHT
}

\section{INCLUSIÓN DIGITAL, CONTROLES, VIGILANCIAS Y LÍNEAS DE FUGA}

Karla Saraiva

\section{RESUMO}

O objetivo deste artigo é discutir a noção de inclusão digital a partir da problematização da internet como um campo de lutas, onde se dá tanto a produção do comum pela multidão e a constituição de novos espaços de liberdade, quanto a ação de mecanismos de controle e de vigilância eletrônica que visam privatizar o comum e assujeitar os indivíduos. Sugere-se uma ampliação na noção de inclusão digital, superando um entendimento restrito à disponibilidade de acesso, ao letramento digital e à capacitação para o adequado uso dos recursos e incluindo a instrumentalização dos indivíduos com conhecimentos técnicos sobre o funcionamento da internet. Pretende-se com isso construir uma cidadania digital que possibilite a participação política efetiva na esfera das tecnologias digitais. Indica-se, ainda, a conveniência de realizar essa ação por meio das escolas, deslocando a noção de uma inclusão digital voltada para classes desfavorecidas para algo necessário a todos os alunos.

PALAVRAS-CHAVE: Inclusão digital. Controle. Cidadania. Educação.

\begin{abstract}
The purpose of this article is to discuss the concept of digital inclusion starting from the problematization of the internet as a field of struggles where there is both the production of the common by the multitude and the creation of new spaces of freedom, and the action of control mechanisms and electronic surveillance aimed at privatizing the common and submitting individuals. We suggest an expansion on the notion of digital inclusion, overcoming an understanding restricted to availability of access, digital literacy and training for proper use of resources and including instrumentalization of individuals with expertise on the functioning of the internet. The purpose of this is developing a digital citizenship that enables the effective political participation in the sphere of digital technologies. We indicate also the convenience to perform this action through schools, displacing the notion of a digital inclusion focused on disadvantaged classes to something necessary for all students.
\end{abstract}

KEYWORDS: Digital inclusion. Control. Citizenship. Education

\section{RESUMEN}

El objetivo de este artículo es discutir la noción de inclusión digital a partir de la problematización de internet como un campo de lucha, donde tiene lugar tanto la producción de lo común por la multitud y la constitución de nuevos espacios de libertad, como la acción de mecanismos de control y de vigilancia electrónica que tienen como objetivo privatizar lo común y convertir a los individuos en sujetos. Se sugiere una ampliación en la noción de inclusión digital, superando un entendimiento restricto a la disponibilidad de acceso, a la alfabetización digital y a la capacitación para el uso adecuado de los recursos, incluyendo la instrumentalización de los individuos con conocimientos técnicos sobre el funcionamiento de internet. Con ello se pretende construir una ciudadanía digital que haga posible la participación política efectiva en la esfera de las tecnologías digitales. Se indica, incluso, la conveniencia de realizar esta acción a través de las escuelas, transfiriendo la noción de una inclusión digital centrada en las clases desfavorecidas a algo necesario para todos los alumnos.

PALABRAS CLAVE: Inclusión digital. Control. Ciudadanía. Educación. 


\section{INTRODUÇÃO}

De acordo com Lopes (2007, p.11), "inclusão e exclusão são invenções de nosso tempo. Invenções completamente dependentes e necessárias uma para a outra”. Os fatores que têm sido considerados como condições de exclusão social são cada vez mais abrangentes. A fabricação de situações chamadas de exclusão social não para de crescer. E os processos considerados estratégias de inclusão não cessam de multiplicar-se. Segundo Castel (2007), nos anos 1990 aconteceu uma explosão dos usos do termo, enfraquecendo sua potência política e analítica. Sua excessiva polissemia corrói sua potência conceitual. Os conceitos de exclusão e inclusão são uma arena de disputa de significados, em que estão em jogo concepções de sociedade e de mundo.

É também nos anos 1990 que emerge a ideia de exclusão digital, chamada em inglês de digital divide, e, por conseguinte, é nesta época que se passa a discutir ações para promover a inclusão digital. Considerando a exclusão digital como uma das facetas da exclusão social, é possível compreender que também este conceito está imerso em um campo de lutas. A noção do que seja a in/exclusão digital varia não apenas entre os diferentes grupos, mas também ao longo do tempo, tendo em vista as transformações das relações entre sociedade e tecnologias digitais. Contudo, de modo geral, a noção de inclusão digital está ligada ao uso da internet. Parece haver certo consenso de que a utilização de artefatos digitais que não tenham conexão com a internet não constitui situação aceitável de inclusão digital.

O propósito deste artigo é discutir o entendimento de inclusão digital a partir da problematização da internet como um campo de lutas, onde se dá tanto a produção do comum pela multidão e a constituição de novos espaços de liberdade, quanto a ação de mecanismos de controle e de vigilância eletrônica que visam privatizar o comum e assujeitar os indivíduos. Na seção seguinte, mostro como a internet se constitui a partir de um modelo surgido no bojo das lutas antidisciplinares dos anos 1960, sendo posteriormente reapropriada por outras estratégias de controle. A seguir, problematizo os entendimentos acerca da noção de inclusão digital e seus efeitos. Finalizo o artigo discutindo possibilidades de atuação da escola na promoção da inclusão digital a partir de um modelo mais abrangente, capaz de fomentar a cidadania digital.

\section{INTERNET, CONTROLE E LINHAS DE FUGA}

A invenção e popularização da internet promoveram profundas, abrangentes e irreversíveis transformações na sociedade contemporânea. Mesmo considerando que apenas 45\% da população mundial seja usuária da internet no ano de 2016 (INTERNET LIVE STATS, 2016), é possível afirmar sua importância tendo em vista o modo como interviu nos processos produtivos, financeiros e políticos nos últimos anos, atravessando-se, portanto, não apenas na vida e na subjetividade daqueles que têm acesso à rede mundial, mas na população em geral. 
O surgimento da internet remonta aos anos 1960, quando foi iniciado nos EUA um projeto de pesquisa, denominado de Arpanet, que tinha por finalidade permitir o compartilhamento de tempo de computação entre diversos institutos de pesquisa. Entretanto, isso parece ter sido apenas uma justificativa aparente, apresentada ao congresso para sua aprovação e para concessão de verbas. A intenção dos pesquisadores que propuseram o projeto, segundo algumas declarações posteriores, seria de promover uma comunicação por meio de computadores capaz de interligar todo o planeta. Esses pioneiros visionários sonhavam de alguma maneira transformar o mundo pela comunicação informatizada (CASTELLS, 2003).

Entretanto, foi necessário um longo caminho para a consolidação da rede mundial como uma tecnologia acessível ao público em geral. Foi apenas em meados dos anos 1990 que a internet passou a ser comercializada, permitindo a difusão dessa tecnologia para além do ambiente acadêmico. A comercialização da internet marca o início de sua inserção na sociedade de modo massivo, produzindo transformações profundas em pouco mais de duas décadas. De acordo com Silveira (2010, p.65)

[...] a maior parte da tecnologia informacional, aparentemente neutra, é a universalização do que Richard Barbrook (2001) denominou de "ideologia californiana". As ideias liberais fundidas aos sonhos libertários e anarquistas presentes na cultura norte-americana estão concentradas nas regras de operação da rede e em suas arquiteturas de comunicação, ou seja, constituem os protocolos técnicos da internet.

Essa afirmação vem ao encontro das pesquisas desenvolvidas no campo conhecido como Estudos Culturais da Ciência, que mostram a estreita ligação entre a cultura de uma época e a produção do conhecimento científico (WORTMANN, VEIGA-NETO, 2001). Neste caso específico, os valores e a visão de mundo do grupo de cientistas que conceberam a internet orientaram para a produção de um determinado tipo de organização da rede. Aqui, é importante notar que a ligação da internet com ideias libertárias de seus criadores não reside no nível do conteúdo, mas de sua arquitetura, de sua concepção técnica. Uma rede sem centralidade, em que todos os nós podem se comunicar entre si sem a necessidade de um mediador, permitindo interações imediatas, parecia a este grupo uma forma de fugir, ou ao menos dificultar, os processos de vigilância. Este fato pode ser comprovado pela dificuldade que países com regimes ditatoriais têm em controlar a comunicação via web.

A rede descentrada mostrou-se efetivamente eficaz como contraconduta disciplinar, funcionando, naquele momento, como linhas de fuga às relações de poder, tendo em vista que a sociedade da época de sua criação, nos anos 1960 e 1970, ainda era fortemente dominada pelo que Foucault (1999) chamou de mecanismos disciplinares. De acordo com esse autor, a disciplina funciona pela vigilância hierárquica, que necessita distribuir os indivíduos no espaço, fixando-os em seus lugares e cortando a comunicação, de modo que o posto central onde estaria o vigia consiga manter toda essa multiplicidade sob o olhar. A vigilância, em conjunto com procedimentos de exame, produz dossiês sobre cada um, possibilitando a sanção de eventuais infrações. A disciplina controla rigidamente as comunicações e as ações \begin{tabular}{l|l|l|l|l|l|l} 
(C) ETD - Educ. Temat. Digit. & Campinas, SP & v.18 & n.4 & p. 922-941 & out./dez.2016 & ISSN 1676-2592
\end{tabular} 
individuais, atuando de modo microfísico. O descentramento da rede que dificulta a vigilância, também oblitera a produção de dossiês individuais e, ao invés de impedir, incentiva a comunicação e o deslocamento dos corpos.

Cabe sublinhar que esta forma distribuída e descentrada de rede não seria a única possível. Apesar de estarmos tão habituados a essa estrutura, outras formas de organização poderiam ter sido adotadas, com destaque para as redes cujo funcionamento se dá a partir de um nó central que distribui informações e medeia a comunicação dos nós periféricos. Esta foi a proposta da rede francesa Minitel, desenvolvida nos anos 1970 e disponibilizada para o público em 1983 (GONZALEZ; JOUVE, 2002) ${ }^{1}$. Este tipo de estrutura de rede, ao contrário do anterior, potencializa os processos de vigilância e de construções de dossiês individuais, isto é, de disciplinamento, uma vez que a capacidade humana de vigiar e de organizar dados seria ampliada de modo quase incomensurável pela tecnologia digital. Ainda que os indivíduos não tivessem restritos a um espaço celular, a arquitetura rígida e centralizada fixaria lugares no ciberespaço, tornando possível o exercício de uma vigilância eletrônica capaz de coletar dados pormenorizados de cada terminal para compor um dossiê e, se necessário, para impor sanções.

Contudo, o poder tira sua força de sua capacidade de transformação. É possível identificar nos anos 1960 e 1970, além da invenção desta rede distribuída e descentrada, uma série de acontecimentos que irrompem afetando e questionando os mecanismos disciplinares. De acordo com Lipovetsky (2004), no pós-guerra ocorre uma expansão extraordinária da renda, principalmente na Europa e nos EUA, que serve como fomento para o surgimento de uma cultura libertária, hedonista, antiautoritária. Essa cultura dá sustentação a acontecimentos como o maio de 1968 na França, o movimento hippie norte-americano e o já referido ideário libertário californiano. "As diversas lutas convergiram contra um inimigo comum: a ordem disciplinar internacional” (HARDT; NEGRI, 2002, p.282). São esses acontecimentos que provocam fissuras no arcabouço disciplinar, tendo como um de seus efeitos a emergência de novas estratégias de poder. Na medida em que as sociedades das últimas décadas do século $\mathrm{XX}$ foram tecendo contracondutas para escapar da vigilância disciplinar, novas estratégias de poder foram sendo inventadas. Formas de exercício de poder menos visíveis, menos coercitivas, mais complexas, mais sutis, mais positivas. Como já afirmou Deleuze (1992, p.221), “os anéis de uma serpente, são ainda mais complicados que os buracos de uma toupeira".

Assim, as fortes reações às organizações disciplinares promoveram a emergência de procedimentos sofisticados para realizar a condução das condutas, que utilizam como uma de suas principais estratégias a produção interesses dos sujeitos. Ou seja, estratégias sutis de convencimento que fazem com que os sujeitos assumam que os interesses daqueles que exercem o poder são os seus próprios interesses, dispensando a vigilância em prol de mecanismos de subjetivação e de verificações sistemáticas. A organização do trabalho, por

\footnotetext{
${ }^{1}$ A rede Minitel foi desativada, definitivamente, em 2012.
} 
exemplo, gradativamente começa a assumir novas configurações que relaxam obrigações como cumprimento de horários e obediência a rígidos regulamentos, enfatizando a responsabilidade pessoal e a necessidade de que cada um gerencie seu próprio trabalho para atingimento de metas.

De acordo com Hardt e Negri (2002), as lutas contra a ordem disciplinar fizeram com que o capital reagisse de duas formas. Primeiramente, por meio da repressão dessas lutas, estratégia que se mostrou de eficácia limitada. Em seguida, passou a integrar ao seu funcionamento as invenções da multidão, suas contracondutas e o próprio objetivo de suas lutas. O capitalismo, de acordo com esses autores, orienta-se sempre para o lucro, funcionando de forma reativa. Isso significa que as transformações do capitalismo que se desenvolvem desde o século passado e se materializam nas transformações do trabalho e da produção, não foram inventadas por capitalistas, mas pelas forças que constituíram as lutas antidisciplinares, forças dissidentes, que não estavam prioritariamente organizadas pelas instituições de lutas disciplinares, como os sindicatos, mas dispersas pelos diversos movimentos culturais. Estavam entre os sujeitos, principalmente jovens, que rejeitavam o trabalho regular e estável, que contestavam as relações de gênero e a composição familiar, que desejavam uma dinâmica profissional mais criativa e flexível, com menos rotina e subordinação e mais autonomia. Esse movimento permite ver com clareza como economia e cultura funcionam estreitamente ligadas, sendo que as transformações culturais ecoam nos processos econômicos e vice-versa.

Os gritos que clamavam por liberdade e autonomia foram ouvidos pelos capitalistas, que iniciam um processo sem volta de dissolução do sólido casamento moderno entre capital e trabalho, produzindo novas relações passageiras e descomprometidas. $\mathrm{O}$ trabalho vai sendo desregulamentado e precarizado. Os sonhos de liberdade acabam por tornarem-se pesadelos de insegurança, que mais uma vez beneficiam o capital (HARDT; NEGRI, 2002). Esse ambiente crescentemente hostil às práticas disciplinares fez surgir outros modos de governar os sujeitos que fazem uso intensivo justamente da rede sociotécnica que é a internet, aproveitando-se de sua estrutura descentralizada para criar novas relações de sujeição. Para absorver as novas composições culturais, o capital utiliza-se de tecnologias gestadas nessa nova lógica. As geometrias inventadas como linhas de fugas da disciplina constituem o substrato onde se apoiam as novas formas de poder. Conforme aponta Deleuze (1992), as organizações disciplinares serviam-se energéticas, que estavam imbricadas com a disciplinarização dos corpos, enquanto as organizações que surgem nessa nova cultura utilizam as tecnologias digitais, que permitem um governo mais sutil dos indivíduos.

A essas novas formas de governar os sujeitos, de conduzir suas condutas, Deleuze (1992) chamou de controle. O controle pode abandonar a vigilância, pois institui uma "uma rivalidade inexpiável como sã emulação, excelente motivação que contrapõe os indivíduos entre si" (Deleuze, 1992, p. 221). A partir de outra abordagem, Foucault (2008) indica algo semelhante. Para ele, a governamentalidade neoliberal tem como princípio de inteligibilidade a concorrência, que atravessa todas as relações. Portanto, ao estimular uma competição 
infindável entre todos, o que foi possível a partir da flexibilização do trabalho, instituindo remunerações variáveis, prêmios e outras vantagens, o capital livrou-se do encargo das vigilâncias e tornou-se um árbitro dos processos concorrenciais, valendo-se das sofisticadas máquinas digitais. Portanto, ao instituir-se o controle, acontece uma redefinição do trabalho e da produção. Gradativamente, o trabalho fabril, que funcionava como o paradigma de trabalho na Modernidade, cede terreno para o chamado trabalho imaterial (HARDT; NEGRI, 2005). Um tipo de trabalho que não apela predominantemente para as forças mecânicas do corpo, mas para as capacidades intangíveis do cérebro. $\mathrm{O}$ trabalho imaterial é característico da área de serviços, do trabalho afectivo, da indústria criativa, do marketing, da pesquisa e da inovação. Mas também invade a indústria, ao tirar o operário do trabalho mecânico, realocando-o no posto de programador de máquinas de controle numérico, e a agricultura, ao disponibilizar sofisticadas tecnologias para o trabalho no campo.

De acordo com Lazzarato (2006), o funcionamento do controle fundamenta-se em três fenômenos: a cooperação entre cérebros, por meio de fluxos e formando redes; o uso de dispositivos tecnológicos que permitem a ação de cérebros sobre cérebros a distância (o que se inicia timidamente com o telégrafo e vai crescendo até a internet); e os processos correspondentes de subjetivação e sujeição, que produzem os públicos. Ainda segundo esse mesmo autor, a invenção é sempre resultado da colaboração entre cérebros, ainda que essa colaboração não seja, em geral, pensada e planejada como tal. A colaboração nasce dos processos de afecção mútua dos cérebros. Portanto, a invenção nunca é individual, ainda que ela possa ganhar materialidade por meio de um indivíduo. Assim, as tecnologias que permitem a intensificação dos processos colaboração entre cérebros aceleram as invenções, fazem proliferar as inovações.

Assumindo serem razoáveis essas premissas, é necessário reconhecer que a inovação e a invenção não são criações de empresas, mas de coletivos organizados em forma de rede que transbordam largamente o escopo empresarial. Por esta razão, Lazzarato (2006) vai afirmar que hoje a produção de valores não tem como lócus privilegiado o trabalho utilizado na (re)produção de bens, mas o agenciamento da invenção, pela captura da criação do comum e efetuação de possíveis. Ou seja, o que o capital hoje expropria não é o trabalho do operário, mas a invenção da multidão. Portanto, os antigos métodos de resistência de expropriação do trabalho, baseados, sobretudo, na organização sindical, perdem força no cenário atual. É necessário inventar novas formas de resistência que consigam municiar a multidão contra a apropriação de seu intelecto coletivo, de seus processos criativos.

Nesse cenário, ainda segundo Lazzarato (2006), consolida-se uma nova forma de exercício de poder, cuja emergência pode ser vislumbrada já no final do século XIX. É um poder que já não pretende fixar os corpos no espaço e cortar a comunicação, como acontecia com a disciplina, nem tampouco intervir sobre o meio para garantir a segurança, como é o caso do que Foucault (2008) chamou de biopoder. Seu alvo não é nem o corpo individual, nem a população. É um poder bastante difuso, complexo e sutil, relacionado com os dispositivos de controle. Ele é exercido sobre uma multiplicidade chamada de público, 
atuando sobre a atenção e a memória. Ou seja, é um poder que passa pelo cérebro para capturar o corpo. A essa modalidade de exercício de poder, o autor denomina de noopoder. A internet constitui-se em uma eficaz correia de transmissão para o noopoder. Ainda que não seja absolutamente necessária para seu exercício, sua emergência potencializou amplamente a afecção dos cérebros para formação de públicos, capturando mais facilmente as subjetividades e levando-as a assumirem determinadas identidades, conduzirem-se de determinadas formas e alinharem-se com determinadas opiniões.

A cooperação entre os cérebros que produz a invenção e a inovação se valem daquilo que Boutang (2012) chamou de polinização, utilizando uma analogia com o trabalho das abelhas. O processo de polinização realizado por esses insetos seria responsável por grande parte da reprodução da flora. Entretanto, apesar da importância da polinização, a economia tradicional não computa esse valor. A única produção que é quantificada nessa perspectiva é a de mel e cera. Processos como a polinização, que representam importantes fatores econômicos, mas que são de difícil quantificação por não serem fruto do esforço direto e planejado, são chamados de externalidades. As externalidades têm papel cada vez mais importante na economia e, apesar da dificuldade de mensurá-las, torna-se impossível não reconhecê-las. Para Boutang, a polinização torna-se fundamental quando o capitalismo se redesenha como capitalismo cognitivo, caracterizado pela desmaterialização da produção, pela importância capital das tecnologias digitais, pelo deslocamento do valor para os bens imateriais. Essa nova forma de acumulação, "captura, através dos dispositivos digitais do tipo web 2.0, uma parte das externalidades positivas resultantes da atividade de polinização da multidão humana e viva" (BOUTANG, 2012, p. 82).

De acordo com esse autor, os processos de cooperação nas redes digitais alimentam o que ele chama de economia da dádiva, colocando as trocas comerciais em segundo plano. A economia da dádiva não se constitui necessariamente por uma decisão, mas pela configuração das produções por meio da polinização. É impossível isolar individualidades quando a criação depende da interação contínua. Essas produções são chamadas por Boutang (2012) de imateriais 2 ou imateriais moles. Ao contrário dos imateriais 1 ou imateriais duros, que consistem em conhecimentos e produtos reconhecidos e com direito de propriedade, os imateriais 2 resistem à codificação. Os imateriais 2 abrangem formas mais ou menos fragmentárias de conhecimento: encontram-se nessa categoria tanto o software livre, fruto do trabalho coletivo de uma comunidade hacker, e as produções artísticas, científicas e literárias distribuídas por meio de copyleft, assumindo de modo voluntário a economia da dádiva, quanto as produções involuntárias de ideias, opiniões e afectos nos processos de colaboração entre cérebros, potencializados por ferramentas oferecidas na web, como grupos de discussão e redes sociais. Esta produção do comum de forma involuntária tende a ser apropriada, privatizada e mercantilizada pelas forças do capitalismo cognitivo, convertendo-se de imateriais 2 em imateriais 1, caso não sejam pensadas estratégias específicas para sua proteção. A produção da multidão torna-se propriedade privada de empresas, sem que seu valor beneficie a força criadora. 
Portanto, a questão que se coloca para este artigo é pensar a inclusão digital não apenas como a introdução de usuários no uso das tecnologias digitais e, em especial, da internet. É pensá-la, também, como forma de instrumentalizar os indivíduos para que construam linhas de fuga dos mecanismos de controle que tentam continuamente apropriar-se e privatizar o comum construído por meio das redes digitais, que buscam continuamente transformar os rastros da cooperação em bancos de dados com alto valor de mercado e que se esforçam por bloquear as possibilidades de construção de novos espaços de liberdade.

\section{A EMERGÊNCIA DA NOÇÃO DE INCLUSÃO DIGITAL}

Por meio da inclusão social, seria possível a construção de uma sociedade democrática, na qual todos conquistariam sua cidadania, a diversidade seria respeitada e haveria aceitação e reconhecimento político das diferenças, de acordo com narrativas que hoje vêm circulando nas mais diversas instâncias. Contudo, a partir de algumas problematizações atuais, é possível compreendermos que o imperativo da inclusão é bem mais complexo e problemático do que essa premissa bem intencionada. Conforme Lopes (2009), a emergência da noção de inclusão estaria imbricada com a consolidação da governamentalidade neoliberal que, como já mostrou Foucault (2008), está implicada no fomento do desejo de cada um em participar do jogo econômico. É por meio da inclusão que se pode governar sujeitos que, de outro modo, teriam dificuldade de serem alcançados pelos dispositivos de segurança que regulam a vida da população, criando condições para que participem do mercado. Contudo, não se deve pensar que a inclusão visa igualdade: colocar todos no jogo não significa colocar todos nas mesmas condições. A isso, Lazzarato (2011) denomina governo das desigualdades, ou seja, incluir para governar e manter as desigualdades, pois são as desigualdades que alimentam a concorrência, princípio de inteligibilidade da governamentalidade neoliberal.

De acordo com Hardt e Negri (2002), a inclusão como um imperativo trabalha com a ideia de que todos são bem-vindos dentro de suas fronteiras, independentemente de raça, religião, cor, gênero, orientação sexual, etc. $\mathrm{O}$ imperativo da inclusão, aparentemente, aceita todos e é indiferente às diferenças. A inclusão universal consegue pôr de lado "diferenças que sejam inflexíveis ou inadministráveis, e que podem dar origem a conflito social" (HARDT; NEGRI, 2002, p.217). Os autores afirmam que "pôr de lado as diferenças significa tirar o potencial das diversas subjetividades constituintes" (HARDT; NEGRI, 2002, p.218). Nesse espaço público, supostamente neutro de poder, é que se estabelece e se legitima uma noção universal de direito que forma o âmago do que eles chamam de Império, uma substância política, descentrada e intangível, que regula as trocas globais e constitui-se em instância máxima de governamento na ordem atual, atravessando e articulando o molar e o molecular. Hardt e Negri (2002, p.218) ainda acrescentam que “o Império é uma máquina de integração universal [...] convidando todo mundo para entrar pacificamente em seus domínios. $\mathrm{O}$ Império não reforça suas fronteiras para afastar os outros; de preferência, puxa-os para dentro de sua ordem pacífica". 
Portanto, assumo a inclusão como uma estratégia de condução de condutas que visa produzir subjetividades capazes de serem capturadas pelos mecanismos de controle e pelos os dispositivos de segurança atuais. Neste quadro, não é difícil perceber a importância da inclusão digital. Se o controle funciona a distância, por meio de sofisticadas máquinas, atuando sobre a memória, a exclusão digital significa não apenas exclusão de uma rede sociotécnica de produção do comum e de conversação, como também uma fuga dos mecanismos de controle. A exclusão digital torna mais difícil capturar as subjetividades contemporâneas.

De acordo com Saraiva e Santos (2009, p.55), "o entendimento do que seja inclusão digital - bem como para que, como e por quem deva ser realizada - é um campo de debates". Entretanto, existe uma posição quase unânime que a associa ao uso da internet, conforme já mencionei antes. Dito de outro modo, não se associa a inclusão digital a um uso qualquer de computadores e outros gadgets, mas a um uso que implique o acesso à rede mundial de computadores. Um equipamento desconectado pouco valor teria, pois não permite a integração nas redes sociotécnicas, bem como o exercício desse poder que se exerce a distância sobre a memória e a atenção.

\begin{abstract}
O próprio termo inclusão nos leva a pensar na espacialidade: incluir é trazer para dentro, encerrar. Segundo Veiga-Neto e Lopes (2007), as políticas de inclusão são efetivadas colocando-se todos os corpos num mesmo espaço, não necessariamente físico, mas simbólico e político. Para que haja inclusão, todos precisam estar juntos. O estar juntos, o posicionamento de todos dentro de um mesmo espaço, também se constitui como uma operação que permite conhecer esse outro que estava na exterioridade, produzir saberes sobre ele, categorizá-lo. Trazer o outro para perto, torna possível governá-lo. A noção de inclusão digital, sob esse ponto de vista, teria sua emergência associada à espacialização da internet. Seria necessário trazer para esse espaço aqueles que estão fora, deixando-os ao alcance de um certo tipo de governamentalidade [tornada possível pela internet] (SARAIVA; SANTOS, 2009, p. 56)
\end{abstract}

A partir dessas considerações, é possível tensionar a noção de inclusão digital, reconhecendo que, se por um lado, ela se constitui em uma condição de possibilidade para melhorar a qualidade de vida dos sujeitos, por outro lado, ela coloca em movimento estratégias de controle rizomático muito sofisticadas e quase invisíveis. São estratégias que permitem conduzir a conduta dos indivíduos sem qualquer resquício de coerção, apelando para mecanismos de poder, cuja sutileza torna difícil sua percepção e, portanto, a construção de contracondutas. "Incluir no ciberespaço, colocar todos nesse plano alternativo da existência, significa multiplicar os agenciamentos e interpelações a que esses sujeitos estão submetidos, enredando-os em novas malhas de poder" (SARAIVA; SANTOS, 2009, p.56).

Apesar dos mecanismos de poder que são acionados pela inclusão digital serem discretos e pouco perceptíveis, é importante destacar que o poder não é um bloco único e compacto que se abate sobre os indivíduos, mas um conjunto de estratégias que visa agir sobre as ações dos outros. Ou seja, as tecnologias de dominação não são absolutas e seus efeitos não são inescapáveis. Desse modo, é possível pensar que o acesso à cibercultura 
coloca os indivíduos ao alcance do controle, mas também potencializa linhas de fuga. E é a partir desse pano de fundo que convido a pensar a in/exclusão digital.

A noção de exclusão digital emerge nos anos 1990, nos EUA. Segundo Bulguer (2007, tradução minha),

\begin{abstract}
A internet estava sendo pensada como tão cheia de possibilidades que qualquer um que ficasse fora dessa revolução estava condenado a uma vida de alienação desconectada, oportunidades perdidas e pobreza de informações, enquanto aqueles que se deleitam com o brilho de um monitor que exibe o Yahoo! eram vistos como indivíduos sofisticados, chiques e informados, que fizeram a prudente opção de estarem conectados. Ninguém, assim se entendia, poderia ser privado da internet, de seu plano alternativo de existência (ciberespaço) e de suas possibilidades ilimitadas de uma rede humana infinita.
\end{abstract}

Nesse primeiro momento, a única preocupação era dar condições de acesso a todos. Portanto, a exclusão digital era, como frequentemente é até hoje, associada à pobreza e à falta de recursos materiais. O governo brasileiro parece compartilhar dessa visão, uma vez que declarar que promove a inclusão digital

para que o cidadão exerça a sua participação política na sociedade do conhecimento. As iniciativas nessa área visam garantir a disseminação e o uso das tecnologias da informação e comunicação orientadas ao desenvolvimento social, econômico, político, cultural, ambiental e tecnológico, centrados nas pessoas, em especial nas comunidades e segmentos excluídos (BRASIL, 2016a).

Este excerto mostra a relação entre inclusão digital e cidadania, um termo utilizado à exaustão, mas muito pouco definido e problematizado. Entretanto, se entendermos cidadania como o vínculo que liga os indivíduos ao Estado, revestindo-os de direitos e deveres e necessitando a implícita aceitação do contrato social, é possível afirmar que a inclusão digital seria uma estratégia que aprofunda este vínculo, que estreita os laços e reforça o compromisso do indivíduo com o Estado. Nesse sentido, a inclusão digital torna-se razão de Estado, que tanto fará ações diretas para sua realização, como incentivará e coordenará outras ações parestatais.

De acordo com o excerto, o governo brasileiro reconhece a importância da internet para o desenvolvimento e para a inclusão social, justificando por aí seu empenho em promover a inclusão digital. Porém, cabe salientar que a internet também é importante instrumento para o governo monitorar os cidadãos por meio de processos que, apesar de utilizarem as avançadas tecnologias digitais, são ainda fortemente disciplinares. Ou seja, a relação entre cidadãos e governo mediada pela internet, naquilo que vem sendo chamado de Governo Eletrônico, passa pela vigilância, pelo exame e pelas sanções normalizadoras, retomando as práticas disciplinares por meio de instrumentos digitais. Conforme Silveira (2010, p.77), apesar das tecnologias digitais serem um dos principais suportes do controle, elas também "convivem claramente com formas de dominação baseadas nas tecnologias de poder territorial — principalmente os Estados soberanos — e com instituições disciplinares e suas arcaicas técnicas de vigilância". As tecnologias digitais podem funcionar tanto como

\begin{tabular}{l|l|l|l|l|l|l} 
(C) ETD - Educ. Temat. Digit. & Campinas, SP & v.18 & n.4 & p. 922-941 & out./dez.2016 & ISSN 1676-2592
\end{tabular}


mecanismos de controle, quanto como potencializadoras de processos de vigilância. As práticas governamentais utilizam cada vez mais a internet como instrumento de monitorar a população, o que torna a inclusão digital um imperativo para o bom funcionamento do Estado.

Portanto, a inclusão digital, ao mesmo tempo em que possibilita o acesso a diversas formas de comunicação, a informações, a serviços e a entretenimento, constituindo possíveis espaços de liberdade, coloca os indivíduos ao alcance de mecanismos de dominação que funcionam principalmente pelo controle, mas também por vigilância. "A mesma rede que garante nossa liberdade comunicativa é a que nos controla” e vigia (SILVEIRA , 2010, p.77). A inclusão digital, tal como vem sendo pensada e realizada na maioria das inciativas, constitui-se ao mesmo tempo em estratégia que empodera os indivíduos e em uma ferramenta que permite ao Império (HARDT; NEGRI, 2002) integrar, capturar e controlar a multidão. Cabe, então, problematizar as ações de inclusão digital. O que não significa, de modo algum, uma posição contrária. Acredito que a inclusão digital constitui-se em um avanço para o empoderamento dos indivíduos, porém entendo, também, que é possível inventá-la de outros modos para ampliar ainda mais a produção de espaços de liberdade e a criação de linhas de fuga ao controle e à vigilância eletrônica.

Ao interrogar acerca das práticas de inclusão digital, o olhar é atraído pela instituição escolar. Uma instituição vetusta, criada na Modernidade para dar conta dos problemas que lhes eram próprios (BIESTA, 2002). Hoje, sua eficácia vem sendo permanentemente questionada, não necessariamente para anunciar sua obsolescência, mas, em geral, para cada vez mais anunciar sua importância e a necessidade de nela investirmos esforços e recursos que consigam superar suas limitações. Conforme Saraiva (2013), a escola vem sendo chamada para dar conta de uma infinidade de problemas sociais, contribuindo para o gerenciamento de riscos na Educação. Segundo Smeyers e Depaepe (2008), atualmente estaria acontecendo uma educacionalização dos problemas sociais, ou seja, estaria se consolidando a ideia de que por meio da educação formal seria possível achar a solução para (todos) problemas sociais. Com a inclusão digital, isso não é diferente: "escolas e crianças são públicos prioritários e indispensáveis" (BRASIL, 2004, p.12). Nesse sentido, é possível compreender que a escola constitui hoje um importante elemento nas ações de inclusão digital.

De acordo com Saraiva e Santos (2009), os projetos que visam à inclusão digital no Brasil têm forte relação com a instituição escolar. Por um lado, boa parte das iniciativas passa pela escola. No âmbito do Governo Federal, por exemplo, um dos principais projetos nessa área é o Um Computador por Aluno (UCA) (BRASIL, 2016c), que distribui equipamentos portáteis para alunos da rede pública. Por outro lado, os projetos de inclusão digital que não acontecem nas escolas, muitas vezes a utilizam como modelo para sua organização. Frente a isso, na próxima seção trato da escolarização da inclusão digital, olhando para as práticas atuais e procurando apontar possibilidades para construir outras práticas. 


\section{INCLUSÃO DIGITAL E EDUCAÇÃO}

A inclusão digital está ligada com a educação não apenas por privilegiar a escola como lócus e modelo para sua realização, como também pela crescente importância que vem sendo atribuída ao papel das tecnologias digitais para a formação, seja como instrumentos considerado de inegável e inigualável eficácia para a aprendizagem na educação presencial, seja como meio para realizar a educação a distância, modalidade que se consolida cada vez mais, principalmente no ensino superior. A noção de inclusão digital entra na escola por diversos caminhos. Aqueles que acompanham há mais tempo as discussões sobre o uso de computadores na escola podem perceber que as expressões tecnologias educacionais ou informática na educação que, entre os anos 1970 e 1990, eram amplamente utilizadas vêm sendo cedendo lugar para a noção de inclusão digital. Assim, parece consolidar-se um entendimento de que qualquer uso pedagógico das tecnologias digitais, com destaque para a internet, consiste em uma prática de inclusão digital.

O entendimento acerca do que seja a inclusão digital vem se ampliando desde sua emergência. Em um primeiro momento, o foco estava quase que estritamente ligado à disponibilidade de equipamentos conectados à internet. Ainda que este foco se mantenha, gradativamente começou a ser incorporada a necessidade de capacitar para a utilização, primeiramente em termos técnicos e, depois, também em termos de capacidade de uso crítico das ferramentas. Ao longo do tempo, o número de indivíduos que não usam a internet por falta condições de acesso vem se reduzindo. De acordo com o levantamento realizado pelo Comitê Gestor da Internet (CGI, 2015), em 2014, os motivos mais evocados para não utilizar a internet foram a falta de habilidade, de interesse e de necessidade, sendo o alto custo de acesso apenas o quarto colocado e não ter onde usar o quinto. É importante destacar que a taxa de utilização vem crescendo principalmente por meios alheios a projetos de inclusão digital: há alguns anos, houve um grande contingente de uso de lanhouses e, mais recentemente, ampliou-se o uso de smartphones.

Contudo, os programas de inclusão digital, sejam na escola ou em outros espaços, tendem a focar na oferta de acesso e no que se vem chamando de alfabetização digital. Ou seja, no uso de recursos como email, mecanismos de busca, editores de texto e aplicativos para edição de vídeo, confecção de blogs e outros utilitários, com o objetivo de qualificar para o trabalho, estimular a aprendizagem, renovar a organização pedagógica. Ou, dito de outro modo, a inclusão digital está voltada para estimular a utilização dos recursos digitais, especialmente aqueles ligados em rede. Este entendimento de inclusão digital estaria presente nas políticas públicas nacionais. Quando, por exemplo, o Programa Nacional de Formação Continuada em Tecnologia Educacional anuncia que a capacitação de professores de escolas públicas para a promoção da inclusão digital visa fazê-los "compreender o potencial pedagógico de recursos das Tecnologias de Informação e Comunicação (TIC) no ensino e na aprendizagem em suas escolas" e "identificar as contribuições das TIC para o desenvolvimento de projetos em salas de aula" (BRASIL, 2016b), ele sinaliza orientação que corrobora a afirmação anterior. No mesmo sentido, o site do Programa Um Computador por 
Aluno, possivelmente a mais destacada política em termos de inclusão digital, ao afirmar que “o PROUCA tem por objetivo promover a inclusão digital pedagógica e o desenvolvimento dos processos de ensino e aprendizagem de alunos e professores das escolas públicas brasileiras" (BRASIL, 2016c), reforça a ideia de um uso instrumental das ferramentas tecnológicas.

A percepção de que as políticas públicas de inclusão digital no Brasil estão orientadas por um viés tecnicista e utilitarista é reforçada por Damasceno, Bonilla e Passos (2012), indicando que quando voltadas para a formação de professores, focam na sua utilização como instrumento para promoção da aprendizagem, e quando voltadas para os alunos, focam na instrumentalização para o mercado de trabalho. Porém, esta concepção limitada de inclusão digital não está restrita às políticas públicas. Muitas iniciativas ligadas à iniciativa privada também vão nesta direção. Isso fica muito claro, por exemplo, em um projeto de inclusão digital voltado para indivíduos em situação de exclusão social promovido por uma universidade gaúcha, em cujo site consta:

[...] em termos concretos, incluir digitalmente não é apenas "alfabetizar" a pessoa em informática, mas também melhorar os quadros sociais a partir do manuseio dos computadores. Não apenas ensinando o bê-á-bá do informatiquês, mas mostrar como ela pode ganhar dinheiro e melhorar suas condições de vida (UNIJUÍ, 2016).

Portanto, parece-me razoável afirmar que a inclusão digital vem sendo associada, frequentemente, com trabalho, renda e aprendizagem, tanto no caso de políticas públicas, quanto no caso de iniciativas privadas. Frequentemente, ela é também associada, nas políticas públicas, com cidadania, pois participar do digital seria um elemento importante da inclusão social na atualidade. Apesar de este aspecto transparecer nos documentos, parece-me pertinente o questionamento que fazem Damasceno, Bonilla e Passos (2012) em relação à efetivação deste objetivo nas ações empreendidas.

Destaco que ao trazer estas discussões, não pretendo, nem de longe, esgotar o assunto e reconheço a existência de projetos orientados para outros modos de compreender e realizar a inclusão digital, que reafirmam a polissemia do conceito na atualidade. Entretanto, não seria possível contemplar na extensão deste trabalho um mapeamento mais completo e a discussão das práticas de inclusão digital no país. Minha intenção é apenas mostrar alguns modos bastante recorrentes de significar a inclusão digital, orientado por visões utilitaristas e tecnicistas. Cabe ressaltar que estas visões são colocadas em cheque em diversos discursos acadêmicos, que preconizam uma inclusão digital voltada para um uso que possa produzir novos espaços de liberdade, que estimule a criatividade, a produção coletiva de conteúdos e a participação social. Entre os muitos autores que vêm produzindo discussões neste sentido, cito os trabalhos de Pesce e Bruno (2016); Barreto (2016); Pretto, Rocha, Souza (2011); Bonilla e Oliveira (2011). Saliento, mais uma vez, que estes trabalhos são apenas alguns exemplos que ilustram a amplitude das discussões acadêmicas, contemplando apenas uma pequena parte da alentada produção intelectual sobre o tema no Brasil. Apesar das muitas diferenças entre estes trabalhos, creio que seja possível afirmar que estes pesquisadores 
advogam pelo uso de ferramentas de comunicação que façam da internet algo maior do que um repositório de informações, transformando-a em um artefato para a promoção do empoderamento e de mudanças na vida dos indivíduos. Tais propostas representam avanços importantes na superação do tecnicismo e do utilitarismo, abrindo possibilidades de crítica e de questionamento, bem como de criação de contracondutas em relação às formas dominantes da governamentalidade. Entretanto, mesmo nestes casos, a in/exclusão digital continua restrita aos segmentos menos favorecidos da sociedade, ou seja, permanece associada com a in/exclusão social.

A partir das discussões apresentadas, pretendo, agora, lançar algumas problematizações acerca das relações entre in/exclusão digital e in/exclusão social, em especial no campo educacional. Ainda que a inclusão digital esteja fortemente ligada com a ideia de escola, aparentemente ela só seria necessária em escolas voltadas para crianças de menor renda e em situação de vulnerabilidade. Em escolas privadas, cujo público é constituído prioritariamente por crianças e jovens que convivem com computadores e outros equipamentos portáteis ligados em rede desde sua primeira infância, parece haver o entendimento de que os alunos fazem um uso adequado e pleno das tecnologias. Esses alunos não estariam em posição de exclusão digital pelo seu fácil, amplo e precoce acesso a esses artefatos. Nessas escolas, o uso da informática é integrado ao currículo, podendo, eventualmente, serem realizadas ações para orientar os alunos sobre, por exemplo, posturas adequadas nas redes sociais, evitando que se exponham ou que promovam situações de risco. Não se costuma utilizar o termo inclusão digital para estes casos, ficando o termo restrito às ações desenvolvidas em escolas públicas.

Entretanto, se tomarmos a ideia de uma cidadania digital fundada na participação política sobre os destinos da rede e no entendimento dos efeitos sociais do uso das tecnologias, seria possível pensar que mesmo usuários experientes e frequentes possam estar em posição de exclusão, entendida aqui como a possibilidade de participação plena nas discussões acerca dos rumos da internet e, de modo mais abrangente, acerca das tecnologias digitais. Compreender o funcionamento das tecnologias, as formas como se dá a governança da internet, o modo como operam os aplicativos e software proprietários e livres, as implicações para a economia, a política e a cultura constituem, neste sentido, saberes imprescindíveis para a cidadania digital. Ela exige habilidades além daquelas necessárias para o uso das tecnologias, seja para a busca de informações ou seja para a comunicação e produção de conteúdos, estendendo-se para um campo de saberes ainda hoje considerados especializados e dominados por um conjunto relativamente restrito de sujeitos.

Bustamante (2010) arrola uma série de elementos que seriam constituintes da cidadania digital, dentre os quais, interessadamente, destaco a participação na criação de uma inteligência coletiva como recurso estratégico para desenvolvimento das comunidades; a defesa dos bens comuns, evitando sua mercantilização; e a proteção contra mecanismos de controle e vigilância. A defesa dos bens comuns está estreitamente relacionada com as discussões feita anteriormente acerca da polinização e da transformação dos imateriais 2 em 
imateriais 1 e esta luta também está articulada com a proteção da privacidade, bem como com o desenvolvimento das comunidades. Desse modo, a noção de cidadania digital que tomo neste artigo implica a participação ativa na construção de uma internet menos submetida ao controle, mais democrática e transparente, bem como em alternativas para escapar desses mecanismos de controle e para se reapossar da riqueza das criações coletivas, além de discussões acerca da mercantilização dos imateriais, que conduz, entre outros pontos, a discutir o uso de software livre e proprietário. A partir desta premissa, é possível pensar que ações de inclusão digital se tornariam necessárias em todas as escolas, para todas as crianças e jovens, sejam eles alunos de instituições públicas ou privadas. Empoderar os sujeitos, neste caso, significa provê-los de ferramentas que permitam que sejam protagonistas na grande ágora digital, participando ativamente das discussões que implicam a definição de políticas da rede sociotécnica.

Portanto, para a construção da cidadania digital, no meu entender, deveriam ser realizadas ações que ultrapassem a capacitação dos sujeitos como usuários, tornando-os cientes dos aspectos técnicos das tecnologias digitais. Essas tecnologias deixariam seu lugar de recurso e tomariam o lugar de objeto de estudo. Sustento esta proposta, pois, neste caso, o conhecimento técnico tem valor político, tendo em vista que se constitui em uma arma para a construção de uma rede mais livre e para a defesa do comum produzido pelos processos de polinização da multidão. Creio que as recentes discussões sobre o Marco Civil da Internet no Brasil sejam adequadas para ilustrar isso que defendo. Ele foi proposto por meio de projeto de lei apresentado na Câmara Federal em 2009, buscando regulamentar o uso da internet no país. A redação do projeto foi fruto de um debate organizado pelo Ministério da Justiça em parceria com o Centro de Tecnologia e Sociedade, da Fundação Getúlio Vargas, por meio da plataforma Cultura Digital (BRASIL, 2016d). Em torno deste tema, travaram-se diversas lutas que colocavam em tensionamento posturas mais conservadoras, disciplinadoras, mercantilistas e restritivas com outras mais inclinadas a preservar a liberdade da rede e os direitos dos usuários.

Por falta de conhecimentos para intervir e, até mesmo, acompanhar as discussões, a maioria dos usuários esteve alijada deste processo de tão grande interesse público. Por fim, em 23 de abril de 2014, foi aprovada a lei no 12.965 (CULTURA DIGITAL, 2016). Destacam-se no texto legislativo aprovado (BRASIL, 2014) os seguintes pontos: proteção à privacidade dos usuários (garante a privacidade nas comunicações e a proteção dos dados); liberdade de expressão e retirada de conteúdo do ar (conteúdos só poderão ser retirados mediante ordem judicial, com exceção da "vingança pornográfica"); garantia da neutralidade da rede (os dados que circulam na Internet devem ser tratados igualmente, sem distinção por conteúdo, origem, destino ou serviço); debate público sobre a regulamentação (algumas normas contidas na lei deveriam ser objeto de posterior regulamentação, que ocorreria após debates abertos à participação ampla da sociedade civil).

Um dos pontos mais delicados e nevrálgicos desta lei reside na questão da neutralidade na rede, ou seja, a determinação de que as empresas que fornecem serviços de 
internet devam tratar da mesma forma todos os dados, não podendo discriminar em termos de velocidade ou de cobrança. A quebra da neutralidade permitiria dar preferência para dados de uma determinada empresa, fazendo com que seus sites e serviços fossem acessados mais rapidamente, ou oferecer acesso gratuito a determinados serviços em detrimento de outros. Isso produziria uma completa mercantilização da internet, reduzindo bastante a liberdade dos usuários e aniquilando com a isonomia no tratamento da informação. A aprovação deste ponto foi bastante difícil, pois muitos parlamentares estão ligados às grandes empresas de telecomunicação, que tiveram seus interesses contrariados. Para que este ponto fosse aprovado, foram realizadas campanhas pedindo que os usuários se manifestassem e pressionassem seus representantes legislativos. Tendo em vista que a maioria dos usuários que não conseguiu compreender os prejuízos que teria com a quebra da neutralidade, houve reduzida pressão para que os legisladores assumissem posições que favorecessem a população e não as empresas de comunicação. Caso a adesão fosse maior, possivelmente a aprovação teria sido mais fácil. Cabe notar que as discussões atuais sobre a regulamentação lançam novas ameaças sobre a neutralidade, exigindo um olhar atento para a sua manutenção. Além disto, esta falta de clareza sobre as implicações da quebra de neutralidade da rede leva usuários a apoiarem iniciativas que são, em um primeiro momento, benéficas, como o acesso gratuito a redes sociais por meio de celulares, pois não percebem que no médio prazo a possibilidade de discriminar o fluxo de dados implicará no aumento custo dos serviços que exijam alto fluxo de dados, como os serviços de streaming de vídeo.

Esta falta de conhecimento que restringiu a participação popular no delineamento da lei revela-se, do mesmo modo, perniciosa também em relação à possibilidade de participação nos debates acerca das regulamentações complementares. Desde o início de 2015, esses debates vêm se realizando por meio da plataforma digital, tendo sido concluídas até o momento duas fases. A primeira, realizada entre 28 de janeiro a 15 de abril de 2015, esteve organizada em torno de quatro pontos de discussão: neutralidade de rede; privacidade; guarda de registros; e outros temas e considerações. A segunda, realizada no início de 2016, visa discutir o texto construído a partir das sugestões da primeira fase, que resultou em uma minuta de decreto (BRASIL, 2016d). Os resultados desta segunda fase poderão resultar em novas alterações no texto proposto para o decreto que será editado pela Presidência da República para regulamentar o Marco Civil. Conforme dados constantes na plataforma, cerca de 50.000 pessoas envolveram-se com as discussões da primeira fase (BRASIL, 2016d). Tendo em vista que, segundo o CGI (2015), na época já havia cerca de 70 milhões de usuários de internet no Brasil, é possível afirmar que apenas uma parte muito pequena dos usuários tomou parte nestas discussões. Frente ao cenário atual, considero bastante plausível afirmar que muitos não poderiam participar por terem conhecimentos insuficientes sobre o tema. Evidentemente, mesmo com a capacitação dos indivíduos para compreender o funcionamento da internet e as implicações das escolhas em questão, nem todos participariam. Entretanto, ao menos não seria por falta de competência técnica, mas razões outras. 
A partir deste exemplo, seria possível perceber que mesmo usuários de longa data não estariam, na maioria das vezes, capacitados para compreender as implicações políticas tanto da governança da internet, quanto de suas próprias atitudes e escolhas como usuários. As discussões sobre o Marco Civil são apenas uma situação específica, dentre muitas que vivenciamos hoje e que demandam posicionamentos que necessitam de conhecimentos acerca da rede sociotécnica. A inclusão digital transforma-se, assim, em uma necessidade que ultrapassa o nicho dos excluídos sociais e que vai atravessar-se de modo amplo na sociedade. Isto faz com que todas as escolas devam se ver como responsáveis por promover ações capazes de produzir e consolidar a cidadania digital, traçando linhas de fuga ao controle e à vigilância eletrônica. As tecnologias digitais tomadas como objeto de estudo exigem uma abordagem interdisciplinar, abrangendo tanto o conhecimento do funcionamento técnico desses artefatos, quanto as implicações sociológicas, antropológicas e políticas, permitindo aos sujeitos avaliarem os efeitos das suas decisões, bem como participarem de discussões acerca das políticas em que elas estão implicadas.

Assim sendo, defendo aqui a necessidade de ações de inclusão digital que vão além da disponibilidade de acesso, do letramento digital e do uso de software e aplicativos. Essas ações mais avançadas implicam em instrumentalizar alunos de escolas, tanto da rede pública, quanto da rede privada, com conhecimentos acerca do funcionamento da rede, seus protocolos, sua arquitetura, suas políticas, as implicações no uso de software livre ou proprietário. Ampliar a noção de inclusão digital para que ela passe a abranger estes conhecimentos técnicos não implica apenas em informar os indivíduos sobre $o$ funcionamento dessas tecnologias, mas empoderá-los e torná-los mais capazes de construírem novas armas para essas novas lutas. Instruir os indivíduos sobre os mecanismos de funcionamento da internet é habilitá-los para a luta política multitudinária de apropriação das redes sociotécnicas, de combate da privatização dos processos de polinização e de produção do comum, e para a criação de linhas de fugas dos controles que nos submetem a ditames mercadológicos que invadem de modo insidioso nossas práticas no ciberespaço.

\section{REFERÊNCIAS}

BARRETO, Raquel Goulart. Discursos sobre a inclusão digital. Educação, Porto Alegre, RS, v. 38, n. 03, p. 319-328. set./dez. 2015. Disponível em: 〈http://goo.gl/WTNOsA >. Acesso em: 14 mar. 2016. ISSN 0101-465X.

BIESTA, Gert. Bildung and modernity: the future of bildung in a world of difference.

Studies in Philosophy and Education, v. 21, n. 04-05, p. 343-351. 2002. Disponível em <http://goo.g1/0E9rn2>. Acesso em: 14 mar. 2016. ISSN 1573-191X.

BONILLA, Maria Helena; OLIVEIRA, Paulo Cézar. Inclusão digital: ambiguidades em curso. In: BONILLA, Maria Helena; PRETTO, Nelson (Orgs.). Inclusão digital: polêmica contemporânea. Salvador: EdUFBA, 2011. 188 p. 
BOUTANG, Yann Moulier. Revolução 2.0, comum e polinização. In: COCCO, Giuseppe; ALBAGLI, Sarita. Revolução 2.0 e a crise do capitalismo global. Rio de Janeiro:

Garamond, 2012. 304 p.

BRASIL. Comitê Executivo do Governo Eletrônico. A inclusão digital é indissociável do governo eletrônico. In: Oficinas de Planejamento Estratégico - relatório consolidado. Brasília: Brasil, 2004. Disponível em: 〈http://goo.gl/WGMy1t〉. Acesso em: 14 mar. 2016.

BRASIL. Lei n. 12.965, de 23 de abril de 2014. Disponível em: 〈http://goo.gl/fj8a4q > Acesso em: 14 mar. 2016.

BRASIL. Programa Governo Eletrônico. Inclusão digital. Disponível em: <http://goo.gl/fCMGqH >. Acesso em: 14 mar. 2016.

BRASIL. Ministério da Educação. ProInfo Integrado. Disponível em: 〈http://goo.gl/tpjB3A>. Acesso em: 14 mar. 2016.

BRASIL. Ministério da Educação. Um computador por aluno. Disponível em: <http://goo.gl/ve45uS >. Acesso em: 14 mar. 2016.

BRASIL. Ministério da Justiça. Marco Civil da Internet. Disponível em: <http://goo.gl/EPy78H >. Acesso em: 14 mar. 2016.

BULGER, Kevin. A brief History of the digital divide. Disponível em: <http://goo.gl/mmeECB >. Acesso em: 14 mar. 2016.

BUSTAMANTE, Javier. Poder comunicativo, ecossistemas digitais e cidadania digital. In: SILVEIRA, Sérgio Amadeu da (Org.). Cidadania e redes digitais. São Paulo: Comitê Gestor da Internet no Brasil, 2010. 249 p. Disponível em: 〈http://goo.gl/AIZcwN〉. Acesso em: 21 mar. 2016.

CASTEL, Robert. As armadilhas da exclusão. In: CASTEL, Robert; WANDERLEY, Luiz Eduardo W; BELFIORE-WANDERLEY, Mariângela (Org.). Desigualdade e a questão social. São Paulo: EDUC, 2007. 368 p.

CASTELLS, Manuel. A galáxia da internet. Rio de Janeiro: Jorge Zahar, 2003. 244 p.

CGI. Comitê Gestor da Internet. Pesquisa sobre o uso das tecnologias da informação e comunicação nos domicílios brasileiros. São Paulo: CGI, 2015. Disponível em: <http://goo.gl/L4YcpI>. Acesso em: 14 mar. 2016.

CULTURA DIGITAL. Marco Civil da internet. Disponível em: 〈http://goo.gl/VJO7ml〉. Acesso em: 14 mar. 2016.

DAMASCENO, Handherson Leyltton Costa; BONILLA, Maria Helena Silveira; PASSOS, Maria Sigmar Coutinho. Inclusão digital no Proinfo integrado: perspectivas de uma política governamental. Inclusão Social, Brasília, DF, v. 05 n. 02. jan./jun. 2012. Disponível em: <http://goo.gl/giLsmX >. Acesso em: 14 mar. 2016. ISSN 1808-8678.

DELEUZE, Gilles. Conversações. Rio de Janeiro: 34, 1992. 240 p.

FOUCAULT, Michel. Nascimento da biopolítica. São Paulo: Martins Fontes, 2008. 494 p. FOUCAULT, Michel. Vigiar e punir. Petrópolis: Vozes, 1999. 264 p. 
GONZALEZ, Antonio; JOUVE, Emanuelle. Minitel: histoire du réseau télématique français. Flux, França, v. 01, n. 47. 2002. Disponível em: 〈http://goo.gl/GtNwk4〉. Acesso em: 14 mar. 2016. ISSN 1958-9557.

HARDT, Michel; NEGRI, Antonio. Império. Rio de Janeiro: Record, 2002. 506 p.

HARDT, Michel; NEGRI, Antonio. Multidão. Rio de Janeiro: Record, 2005. 532 p.

INTERNET LIVE STATS. Disponível em: 〈http://goo.gl/O3TIdj〉. Acesso em: 09 mar. 2016.

LAZZARATO, Maurizio. As revoluções do capitalismo. Rio de Janeiro: Civilização Brasileira, 2006. 272 p.

LAZZARATO, Maurizio. O governo das desigualdades. São Carlos, SP: EdUFSCar, 2011. 93 p.

LIPOVETSKY, Gilles. Os tempos hipermodernos. São Paulo: Barcarolla, 2004. 136 p.

LOPES, Maura Corcini. Inclusão escolar: currículo, diferença, identidade. In: LOPES, Maura Corcini; DAL'INGA, Maria Cláudia (Orgs). In/exclusão nas tramas da escola. Canoas: ULBRA, 2007. $231 \mathrm{p}$.

LOPES, Maura Corcini. Políticas de inclusão e governamentalidade. Educação \&

Realidade, Porto Alegre, RS, v. 34, n. 02, p. 153-169. mai./ago. 2009. Disponível em: <http://goo.g1/E7F4L4>. Acesso em: 14 mar. 2016. ISSN 2175-6236.

PESCE, Lucila Maria; BRUNO, Adriana Rocha. Educação e inclusão digital: consistências e fragilidades no empoderamento dos grupos sociais. Educação, Porto Alegre, RS, v. 38, n. 03, p. 349-357. set./dez. 2015. Disponível em: 〈http://goo.gl/kfIdIa〉. Acesso em: 14 mar. 2016. ISSN 0101-465X.

PRETTO, Nelson; ROCHA, Telma; SOUZA, Joseilda. Tabuleiro digital: uma experiência de inclusão em ambiente educacional. In: BONILLA, Maria Helena; PRETTO, Nelson (Orgs.). Inclusão digital: polêmica contemporânea. Salvador: EdUFBA, 2011. 188 p.

SARAIVA, Karla. Educando para viver sem riscos. Educação, Porto Alegre, RS, v. 36, n. 02, p. 168-179. mai./ago. 2013. Disponível em: 〈http://goo.gl/3bgd6X $\rangle$. Acesso em: 14 mar. 2016. ISSN 0101-465X.

SARAIVA, Karla; SANTOS, Iolanda Montano dos. A internet nasce para todos. Textura, Canoas, RS, n. 19-20, p. 51-61. 2009. Disponível em: 〈http://goo.gl/RZz6ck>. Acesso em: 14 mar. 2016. ISSN 2358-0801.

SILVEIRA, Sérgio Amadeu da. Ambivalências, liberdade e controle dos ciberviventes. In: SILVEIRA, Sérgio Amadeu da. Cidadania e redes digitais. São Paulo: Comitê Gestor da Internet no Brasil, 2010. 249 p. Disponível em: 〈http://goo.gl/JTo73〉. Acesso em: 21 mar. 2016.

SMEYERS, Paul; DEPAEPE, Marc. Pushing social responsibilities: the educationalization of social problems. In: SMEYERS, Paul; DEPAEPE, Marc (Orgs.). Educational research: the educationalization of social problems. Bruxelas: Springer, 2008. 244 p. 
UNIJUÍ. Projeto de inclusão digital. Disponível em: 〈http://goo.gl/KE6i5n>. Acesso em: 14 mar. 2016.

VEIGA-NETO, Alfredo; LOPES, Maura Corcini. Inclusão e governamentalidade. Educação \& Sociedade, Campinas, SP, v. 28, n. 100. out. 2007. Disponível em:

〈http://goo.gl/MwFLHF>. Acesso em: 14 mar. 2016. ISSN 1678-4626.

WORTMANN, Maria Lúcia; VEIGA-NETO, Alfredo. Estudos Culturais da Ciência \& Educação. Belo Horizonte: Autêntica, 2001. 224 p.

\section{AGRADECIMENTOS}

Agradeço ao apoio do CNPq, que financiou a pesquisa da qual se originou este artigo, por meio do Edital Universal de 2012.

\section{KARLA SARAIVA}

Doutora em Educação Universidade Federal do Rio Grande do Sul - UFRGS Porto Alegre, RS - Brasil

Professora Adjunta Universidade Luterana do Brasil - ULBRA Canoas, RS - Brasil E-mail: karlasaraiva@via-rs.net

Recebido em: $21 / 03 / 2016$ Aprovado para publicação em: 16/05/2016

\section{Como citar este documento:}

SARAIVA, Karla. Inclusão digital, controles, vigilâncias e linhas de fuga. ETD - Educação Temática Digital, Campinas, SP, v. 18, n. 4, p. 922-941, set. 2016. ISSN 1676-2592. Disponível em: <http://periodicos.sbu.unicamp.br/ojs/index.php/etd/article/view/8644449>. Acesso em: 16 nov. 2016. doi:http://dx.doi.org/10.20396/etd.v18i4.8644449. 